\title{
CONGENITAL CYANOTIC HEART DISEASE: FOLLOW-UP STUDIES IN FORTY OPERATED CASES
}

BY

\author{
J. E. WILSON
}

\author{
From Department $R$, the University Hospital, Copenhagen
}

From January, 1948, to October, 1949, 63 cases of persistent cyanosis of cardiac origin have been operated upon in this department, and it is the purpose of this paper to give a review of some of these cases and the results attained. The first 40 cases operated upon have been selected because it is considered that an insufficient interval has elapsed since operation in the remaining 23 cases to warrant a follow-up examination.

The tetralogy of Fallot is a developmental abnormality of the heart which consists, as the name suggests, of four features: pulmonary stenosis, hypertrophy of the right ventricle, and a dextroposed aorta overriding an interventricular septal defect. The foramen ovale may be open or closed. As a result of the pulmonary stenosis an insufficient amount of blood enters the pulmonary artery system for oxygenation in the lungs, while at the same time the overriding aorta allows the entry into the arterial circulation of venous blood from the right ventricle. These two factors combine to reduce the level of the blood oxygen below the normal, with the production of the classical feature of the disease, persistent cyanosis. The purpose of the operation is to divert into the pulmonary artery system incompletely oxygenated blood from the arterial circulation by a surgically produced channel.

The patients in this series were sent to us from all parts of Denmark. They were investigated in the medical department, in the paediatric department, or in the department of thoracic surgery. They were all subjected to cardiac catheterization in the laboratory of cardiology (under Professor E. Warburg), and blood oxygen saturation estimations and intra-cardiac pressure recordings were made. Angiocardiography has been used in only one of these cases.

\section{Selection of CASES}

In deciding whether to operate or not, three factors were considered. These were: the wishes of the patient or, in the case of children, the wishes of the parent ; the degree of incapacity (largely evaluated on the patient's history); and the age of the patient. This last factor alone was never used as the grounds for a refusal to operate, but it seemed to us reasonable to assume that the adult patient, capable of doing a light, sedentary job, probably had a minor degree of pulmonary stenosis or had established a good collateral circulation, and consequently was better left alone.

In the higher age groups no case was refused operation on the grounds of being too ill or of being too serious an operation risk. On the contrary, the cases operated on represent the worst cases seen. 
Of the 40 cases operated upon, 35 were cases of Fallot's disease (871 \%), two (Cases 20 and 25) of pulmonary stenosis alone with inter-atrial septal defect $(5 \%)$, two (Cases 2 and 40 ) of underdeveloped right ventricle (5\%), and one was a case in which doubt still exists as to the actual pathology, but was thought to be a case of aortic stenosis associated with an inter-atrial septal defect and a small functioning patent ductus arteriosus (Case 37).

Sex Incidence.-The 40 cases included 24 males and 16 females.

Age.-The youngest patients operated upon were 3 years of age (four cases), while the oldest was 36 . The average age was 12 years. The age groups of the patients are given below.

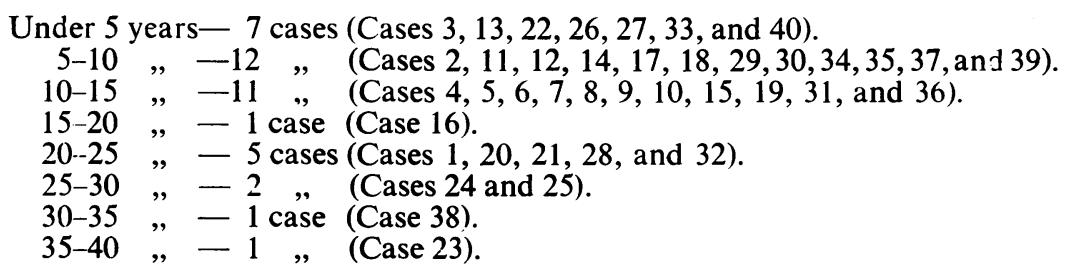

\section{FINDINGS BEFORE OPERATION}

Exercise Capacity.-The assessment of the capacity for exercise is difficult in these patients. An ergometer on the bicycle principle with measurable frictional damping has been used, but the results are not considered satisfactory, especially in the younger age group, largely because "exhaustion" is interpreted by different patients in different ways. In the estimation of exercise capacity we have relied principally on the patient's or parent's history, and have accepted their statements as to how much they were able to do. This has necessitated careful questioning and the fixing of arbitrary levels for the degrees of exercise of which the patients were capable. Those who were totally confined to bed we considered to have an exercise capacity of " nil," while those who were unable to leave their own room have been classed "almost nil." Those who were able to go out a little and were able to walk slowly a distance of 200 metres or so, have been classed as "poor," while those capable of climbing a short flight of stairs without a rest, or those who could walk gently a distance of half a mile, were classed as "fair." Only one case in the series was in regular employment, as a seamstress in a tailoring establishment (Case 25), and she was considered to have a "fairly good" exercise capacity. On this method of grading, the exercise capacities are listed below.

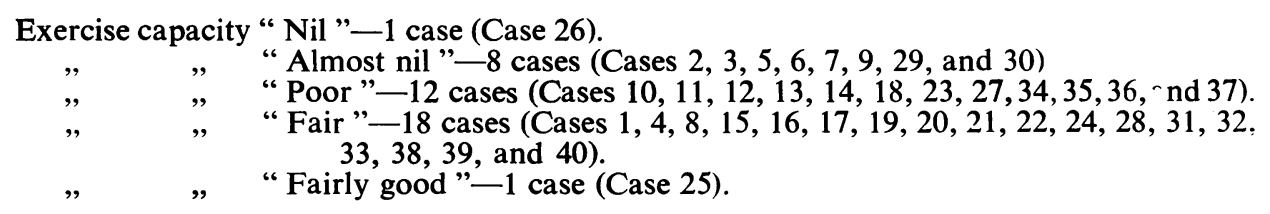

Cyanosis.-The degrees of cyanosis were graded as " marked," " moderate," and "slight."

The cases considered as "marked" showed severe cyanosis of the face and extremities and blue-black cyanosis of the mucous membranes. Those graded as 
"moderate" showed an obvious bluish tinge of the face, lips, ears, and finger tips at rest, while those considered "slight" were those in which cyanosis was noted only in the finger tips and perhaps in the lips.

Of the 40 cases

27 cases had " marked" cyanosis.

10 " " "moderate" " (Cases 4, 6, 9, 11, 12, 13, 17, 21, 28, and 33).

3 " " "slight" " (Cases 25, 32, and 37).

Twenty-two of the cases of "marked" cyanosis, nine of the "moderate," and one of the "slight" category were diagnosed as suffering from Fallot's tetralogy. Of the 40 cases, $24(60 \%)$, were cyanosed at birth, while $16(40 \%)$ did not show cyanosis until periods varying from one month to six years had elapsed after birth. Taussig (1947a and b) has mentioned the importance of the delayed closure of a patent ductus arteriosus as a deciding factor in the appearance of visible cyanosis, but in the course of history-taking one was struck by the frequency with which the first appearance of the cyanosis coincided with the first expenditure of considerable effort, such as that used in the first attempts at walking.

Finger clubbing was seen in 39 of the 40 cases $\left(97 \frac{1}{2} \%\right)$, while a history of squatting was given in $23\left(57 \frac{1}{2} \%\right)$. Fainting attacks with loss of consciousness had occurred in $12\left(42 \frac{1}{2} \%\right)$, while only seven patients complained of "cramps" (17 $\left.\frac{1}{2} \%\right)$.

Erythrocyte Count.-Almost all the cases showed an erythrocyte count above the normal. In eight a count of over $9,000,000$ red cells per c.mm. was found, while in four the count was little above the normal.

A point of interest is that E. A. (Case 6) and J. A. P. (Case 9) were two of the most severely incapacitated of the patients we have seen, neither of these children having left their rooms for a period of about four years. Their red cell counts were $5,420,000$ per c.mm. and 5,220,000 per c.mm., respectively, so it would appear that a polycythaemia may not always occur in the absence of effort, and that it may be, in some cases, of the nature of a "work hypertrophy."

Haemoglobin Level.-An increase in the haemoglobin level was also an almost universal finding in these cases. The highest recorded was that in the case of P.N. (Case 19) of 193\%, while the lowest was $90 \%$ (H. P. J., Case 37).

The large majority of the patients showed a stunting of growth and a weight below the normal for their age. In all cases sexual development had been unretarded.

Clinical Examination of the Heart.-A palpable precordial thrill was present in 12 of the cases, and these were all examples of the tetralogy of Fallot (34\%), and a systolic murmur in some part of the precordial area was heard in 37 cases $\left(92 \frac{1}{2} \%\right)$, 32 of these being Fallot's disease $(91 \%)$; the maximum intensity of the murmur was generally along the left sternal border, especially in the second and third interspaces. In two cases of Fallot's disease no murmur could be heard (Cases 3 and 36), while in a third a continuous murmur in the left axilla was the only finding on auscultation, and this led us for some time to believe that the lesion was an arteriovenous communication in the lung. This was the only case in which angiocardiography was used. 
Radiological Findings.-The radiological picture of the thorax in Fallot's disease is well known and can be briefly described thus: (1) a normal sized or slightly enlarged heart, the enlargement usually affecting the right ventricle, and with a consequent tilting up of the apex of the heart from the diaphragm ; (2) a lack of fullness in the region of the pulmonary conus, so that the left upper border of the heart outline is concave ; (3) lung hilar shadows less marked than normally, and unduly clear lung fields ; (4) the left oblique view of the thorax taken from the front shows an abnormally clear pulmonary window.

In 29 of the 35 cases of Fallot's disease (83\%) a picture approximating closely to the characteristic was seen, while in the remaining six cases little variation from the normal was found. An abnormally clear pulmonary window was seen in only 17 cases of Fallot's tetralogy $\left(48 \frac{1}{2} \%\right)$.

\section{OPERATION}

Anaesthesia.-The difficulties with which the anaesthetist is confronted in these cases are many, but two of the greatest arise directly from the physiological disadvantages of an already low blood pressure and an ever-present danger of anoxia. By virtue of the experience gained in these cases, an anaesthesia technique has been evolved in which an attempt has been made to counteract as far as possible these disadvantages. It is the intention only to describe those methods which have been found to be satisfactory.

All the patients were given pre-operative medication of atropine sulphate and luminal in doses of $\frac{1}{2}{ }_{0}-\frac{1}{0}-\mathrm{gr}$. atropine sulphate and $\frac{1}{2}-1 \mathrm{gr}$. luminal, depending on the age.

In the earlier cases the induction of anaesthesia was by intravenous " narcodorm" (sodium-B-bromallyl-isopropyl-N-metylbarbituric acid), and this was used in 23 cases. Despite the fact that it was given slowly, the blood-pressure-lowering effect of the barbiturate sometimes caused concern, and so the use of " narcodorm " has been discontinued. In one of the deaths (Case 5) its use was considered directly responsible, and induction of anaesthesia is now made with divinyl ether and ether on an open mask.

In the earlier cases nitrous oxide with oxygen and ether was used, but owing to the added risk of anoxia when using nitrous oxide, it was always used with great care, and recently has been given up. From the divinyl ether and ether induction it is the practice to carry on with an ether and oxygen mixture only. All cases have had intratracheal intubation and controlled or assisted respiration. The blood pressure and pulse rate were recorded at five-minute intervals.

Liberal fluid has been given by mouth before operation for a period of about a week, the daily intake being $150 \mathrm{ml}$. per $\mathrm{kg}$. of bodyweight. During operation it was usual to give an intravenous drip of glucose $(6 \%)$ and plasma, usually $500 \mathrm{ml}$. of each. Whole blood was never given.

Curare was used in 23 of the 40 cases, but recently, using the method of anaesthesia described, its use has not been found necessary, and it is now only used on the rare occasion when the degree of mediastinal movement is sufficient to make the vessel suture difficult.

In all cases it was the practice immediately the chest had been opened to inject the vagus and phrenic nerves with "novocaine" of $1 \%$ strength for the former and 
$2 \%$ for the latter. The mediastinal tissues between these structures, and in the line of the subclavian artery, were also infiltrated with $1 \%$ " novocaine."

Method.-The method of operation in this series was that of Blalock, namely anastomosis of the subclavian artery to the pulmonary artery.

Choice of Approach.-Much has been written on the merits of the respective surgical approaches, some preferring the antero-lateral approach, and others the postero-lateral, while some prefer to operate on the side on which the aorta descends, and others on the contra-lateral side.

Analysis of Approaches and Procedures.-Of the series comprising 40 cases, 39 were operated upon, one (Case 5) dying during the induction of anaesthesia. In 33 of the 40 cases (79\%) the aorta was found to descend on the left side (Table I), and in seven $(21 \%)$ on the right (Table II).

TABLE I

Cases with the Aorta Descending on the Left Side

\begin{tabular}{|c|c|c|c|c|}
\hline \multicolumn{3}{|c|}{ Approach } & \multirow{2}{*}{$\frac{\text { No. of Cases }}{25}$} & \multirow{2}{*}{$\begin{array}{c}\text { Case Nos. } \\
2,3,4,6,8,9,11,12,13,15,17 \\
19,20,22,25,26,27,28,29 \\
31,33,34,36,39, \text { and } 40\end{array}$} \\
\hline Left antero-lateral & . & .. & & \\
\hline Left postero-lateral & .. & . & 3 & 1,32 , and 37 \\
\hline Right antero-lateral & .. & .. & 2 & 10 and 35 \\
\hline \multicolumn{3}{|c|}{ Left antero-lateral and right antero-lateral } & 2 & 7 and 24 \\
\hline
\end{tabular}

TABLE II

Cases with the Aorta Descending on the Right Side

\begin{tabular}{|c|c|c|c|c|}
\hline \multicolumn{3}{|c|}{ Approach } & \multirow{2}{*}{ No. of Cases } & \multirow{2}{*}{$\frac{\text { Case Nos. }}{18 \text { and } 30}$} \\
\hline Right antero-lateral & .. & . & & \\
\hline Right postero-lateral & .. & .. & 2 & 16 and 21 \\
\hline Left antero-lateral & .. & . & 1 & 23 \\
\hline Left postero-lateral & $\cdots$ & .. & 1 & 38 \\
\hline \multicolumn{3}{|c|}{ Right antero-lateral and left antero-lateral } & 1 & 14 \\
\hline
\end{tabular}

In Case 7 the chest was first opened on the right side, but the subclavian artery was found to be too short to reach the pulmonary artery. The operation was successfully carried out on the left side six weeks later, while in Case 24 the pulmonary artery was too small in calibre on both sides to allow of an anastomosis being made.

In Case 14 it was found at the first operation that the pulmonary artery was too small for an anastomosis to be made. The chest was opened on the left side six weeks later, and, as on this occasion the subclavian artery was too small, it was 
necessary to use the innominate artery for the anastomosis. This was the only case in which the innominate artery was used.

Blalock prefers to operate on the side of the chest opposite to that on which the aorta descends, because he finds that after the anastomosis has been made the subclavian artery is allowed to reach down to the pulmonary artery without angulation or kinking ; but it is our experience here that quite a marked degree of kinking of the subclavian artery is not incompatible with a very good final result. It would appear that the pressure of the blood at each cardiac systole is sufficient to open up the channel, and indeed this can often be proved by palpation of the vessel at operation.

From the experience gained from the 63 cases operated upon in this clinic it is considered that the factors governing the choice of approach are as follows.

With an aorta descending on the left side in children under the age of 12 years, the left-sided antero-lateral approach through the second or third inter-space gives an excellent exposure. It is found that the advantages of this left-sided approach are that (1) the pulmonary artery is more accessible on the left side than on the right ; (2) the dissection of the subclavian artery is more easily carried out on the left side ; (3) the operation field is not obstructed by other large structures, such as the superior vena cava and the atrium, as is the case on the right side ; and (4) the subclavian artery can be sacrificed without untoward effect.

In the case of an aorta descending on the right side, it is an advantage to use the right postero-lateral approach at all ages, with resection of the fourth or fifth rib. It has been found that with this approach, with the patient lying on the opposite side, the superior vena cava and the atrium are displaced away from the field of operation by their own weight, making the short right pulmonary artery more accessible. Furthermore, it has been found that if the aorta is transposed it is usual to find the great vessels which arise from it also transposed, so that the advantages claimed in Cases 2 and 4 above apply in this instance also.

In patients over the age of 12 years, the postero-lateral approach is used on the side on which the aorta descends, as it has been found that, with the larger anteroposterior diameter of the thorax in these older patients, dissection and the vessel suture are difficult at such depth.

The Anastomosis.-The method of suture used has been that of Blalock, but in the more recent cases, while a continuous suture has been used for the posterior aspect of the anastomosis, separate U-sutures have taken the place of the continuous suture for the anterior aspect, so that, if growth of the anastomotic channel does occur with the growth of the patient, it should not be inhibited by an inelastic suture ring.

Heparin and dicoumarol have not been used, either before, during, or after operation. In only one case was the former used (Case 15) after the patient had developed a cerebral thrombosis in association with a staphylococcal septicaemia 10 days after operation. She died six weeks later.

Anatomical Variations. - In the majority of cases operated upon the anatomy of the subclavian artery and the pulmonary artery was such that an anastomosis could be carried out without undue difficulty.

Vascular pleural adhesions were a fairly common occurrence, but in only one case did they prove an insurmountable difficulty (Case 23), the oldest patient in the 
series, where division of the many adhesions between the lung and the parietal pleura caused quick collapse and death 48 hours later. It would appear that this patient had been dependent on these adhesions for the major part of her pulmonary circulation.

The commonest abnormality encountered in the subclavian artery was that of early division of the artery or excessive shortness, the two conditions often being found together and often being interdependent. In a few cases a branch of the artery had to be used for the anastomosis - with good result-but if it is at all possible to do so we have used the full width of the main trunk even at the expense of some kinking. If there is tension on the suture line we have divided the inferior pulmonary ligament, and we feel that this procedure is worth while. In earlier cases we tried freeing the aorta from its bed, but our experience is that the aorta then tends to move upwards in the thorax thus making matters worse.

Excessive smallness of diameter, or shortness, or early division of the pulmonary artery was seen in nine cases. In one (Case 24) the pulmonary arteries were too small to allow of anastomosis, while in a second, H. V. L. (Case 38), a pulmonary artery was present on one side only, and this was much too small for our purpose. In one (Case 7) it was necessary to operate on both sides because on the first side the pulmonary artery was too small. Shortness of the pulmonary artery, we have found, can usually be overcome by opening the pericardium, and this was necessary in four cases. In one, G. L. A. (Case 32), owing to early branching of the pulmonary artery it was necessary to do an end-to-end anastomosis between the subclavian artery and the largest branch of the former. In four cases it was found impossible to perform an anastomosis. These were: (1) H. M. M. (Case 24), where the pulmonary arteries were too small and an anastomosis was technically impossible. (2) H. P. J. (Case 37), in which it was known that the patient had a patent ductus arteriosus but still had persistent cyanosis. The aorta was extremely small and situated high in the thorax. The patent duct was found to be functioning, but in view of the cyanosis it was felt that it was insufficient. The pathology in this case was doubtful, but a short pulmonary artery and a highly situated aorta precluded any possibility of performing an anastomosis. (3) H.V.L. (Case 38), in which a small pulmonary artery was present on the left side and was totally absent on the right. (4) E. R. J. (Case 23), in which collapse and early death followed the division of the adhesions between the lung and the parietal pleura. In one case, that of H. V. L. (Case 38), the pleural stripping operation (Barrett and Daley, 1949) was carried out.

\section{OPERATION RESULTS}

In this series 40 cases of persistent cyanosis of cardiac origin, including 35 cases of the tetralogy of Fallot, were operated on with five deaths $\left(12 \frac{1}{2} \%\right)$. (The number of cases operated on at the time of writing has reached 63 without further deathsless than $8 \%$.)

Of the five deaths two can be classed as anaesthetic deaths : one, O. R. (Case 5), dying before the operation was started, and the second, K. N. D. (Case 29), dying on the operating table from asphyxiation after completion of the operation due to the premature removal of the intubation tube. 
One death, E. R. J. (Case 23), the oldest patient in the series, followed quickly on the collapse resulting from the division of extensive vascular adhesions between the lung and the parietal pleura.

One death, G. A. J. (Case 21), resulted from an acute left ventricular failure 48 hours after operation. Necropsy in this case showed a small and poorly developed left ventricle and an aorta and pulmonary artery arising entirely from the right ventricle.

One death occurred six weeks after operation in a patient who developed a Staphylococcus aureus septicaemia of unknown origin 10 days after operation (H. R., Case 15).

$$
\begin{aligned}
& \text { Age-Death InCidence }
\end{aligned}
$$

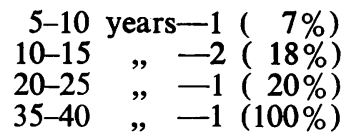

\section{FOLLOW-UP EXAMINATION}

In attempting to assess the result of operation in these cases we have tried as far as possible to view each case as a composite picture. Increase in capacity for exercise is of course the most important and sought-for improvement, but only if it is gained without undue cardiac enlargement; thus in the case of C. H.C. (Case 28) it appeared at first sight that his was an excellent result, and it was surprising to find on radiographs included in the follow-up examination that the overall width of the heart had increased by $4 \mathrm{~cm}$. Similarly in another case, K. E. J. (Case 18), there was little or no improvement in colour, and the haemoglobin level and red cell count showed no change a year after operation, and yet her parents informed us that she was able to walk $10 \mathrm{~km}$. without any distress. Previously she had been unable to leave the house. Gain in height and weight have also been recorded, and by viewing all these factors in each case I have attempted to arrive at an evaluation of the results in my final analysis.

No case was included in which less than three months had elapsed since operation, and only six are included which have not been observed for at least six months. In eight cases six months have passed since operation, and in nine, more than a year.

TABLE III

Cases Examined Three to Six Months after Operation

\begin{tabular}{|c|c|c|c|c|c|c|c|c|c|}
\hline \multirow{2}{*}{$\begin{array}{l}\text { Case } \\
\text { No. }\end{array}$} & \multirow{2}{*}{$\begin{array}{c}\text { Age } \\
\text { (Years) }\end{array}$} & \multicolumn{2}{|c|}{ Gain in } & \multicolumn{2}{|c|}{$\begin{array}{l}\text { Haemoglobin } \\
\text { Level (\%) }\end{array}$} & \multicolumn{2}{|c|}{$\begin{array}{c}\text { Erythrocyte Count } \\
\text { (m. per. c.mm.) }\end{array}$} & \multicolumn{2}{|c|}{ Cyanosis } \\
\hline & & $\begin{array}{l}\text { Height } \\
\text { (cm.) }\end{array}$ & $\begin{array}{l}\text { Weight } \\
\text { (kg.) }\end{array}$ & Before & After & Before & After & Before & After \\
\hline $\begin{array}{l}16 \\
33 \\
35 \\
39 \\
40 \\
27\end{array}$ & $\begin{array}{l}19 \\
3 \frac{1}{2} \\
8 \\
6 \\
3 \\
3\end{array}$ & $\begin{array}{l}1 \\
1 \\
2 \\
2 \frac{1}{2} \\
2 \frac{1}{2}\end{array}$ & $\begin{array}{l}3 \\
1 \frac{1}{2} \\
2 \\
2 \\
1 \frac{1}{2} \\
1\end{array}$ & $\begin{array}{l}165 \\
130 \\
160 \\
160 \\
150 \\
125\end{array}$ & $\begin{array}{l}120 \\
108 \\
120 \\
135 \\
132 \\
115\end{array}$ & $\begin{array}{l}7.4 \\
6.02 \\
9.06 \\
9.63 \\
7.85 \\
7.2\end{array}$ & $\begin{array}{l}5.8 \\
5.6 \\
6.7 \\
5.64 \\
7.12 \\
6.0\end{array}$ & $\begin{array}{l}\text { Marked } \\
\text { Moderate } \\
\text { Marked } \\
\text { Marked } \\
\text { Marked } \\
\text { Marked }\end{array}$ & $\begin{array}{l}\text { Moderate } \\
\text { Slight } \\
\text { Slight } \\
\text { Slight } \\
\text { Moderate } \\
\text { Moderate }\end{array}$ \\
\hline
\end{tabular}


TABLE IV

Cases Examined Six to Nine Months after Operation

\begin{tabular}{|c|c|c|c|c|c|c|c|c|c|}
\hline \multirow{2}{*}{$\begin{array}{l}\text { Case } \\
\text { No. }\end{array}$} & \multirow{2}{*}{$\begin{array}{c}\text { Age } \\
\text { (Years) }\end{array}$} & \multicolumn{2}{|c|}{ Gain in } & \multicolumn{2}{|c|}{$\begin{array}{l}\text { Haemoglobin } \\
\text { Level (\%) }\end{array}$} & \multicolumn{2}{|c|}{$\begin{array}{l}\text { Erythrocyte Count } \\
\text { (m. per c.mm.) }\end{array}$} & \multicolumn{2}{|c|}{ Cyanosis } \\
\hline & & $\begin{array}{l}\text { Height } \\
(\mathrm{cm} .)\end{array}$ & $\begin{array}{l}\text { Weight } \\
\text { (kg.) }\end{array}$ & Before & After & Before & After & Before & After \\
\hline $\begin{array}{r}1 \\
3 \\
8 \\
12 \\
13 \\
17 \\
19 \\
24 \\
25 \\
30 \\
34 \\
36 \\
38\end{array}$ & $\begin{array}{r}20 \\
4 \\
12 \\
9 \\
4 \\
5 \\
14 \\
25 \\
28 \\
7 \\
9 \\
10 \\
32\end{array}$ & $\begin{array}{l}1 \\
1 \\
6 \\
3 \\
9 \\
3 \\
3 \\
- \\
7 \\
4 \\
3 \\
-\end{array}$ & $\begin{array}{l}7 \\
2 \\
7 \frac{1}{2} \\
1 \frac{1}{2} \\
2 \\
1 \frac{1}{2} \\
7 \\
5 \\
3 \frac{1}{2} \\
3 \\
2 \\
2 \\
4\end{array}$ & $\begin{array}{r}165 \\
160 \\
142 \\
110 \\
140 \\
130 \\
193 \\
160 \\
95 \\
150 \\
161 \\
160 \\
155\end{array}$ & $\begin{array}{r}124 \\
165 \\
110 \\
92 \\
105 \\
110 \\
162 \\
138 \\
92 \\
110 \\
111 \\
126 \\
135\end{array}$ & $\begin{array}{l}8.3 \\
9.55 \\
7.3 \\
6.55 \\
6.5 \\
6.3 \\
9.07 \\
8.9 \\
4.4 \\
8.7 \\
9.2 \\
8.4 \\
7.2\end{array}$ & $\begin{array}{l}6.2 \\
8.68 \\
5.7 \\
6.47 \\
5.85 \\
5.9 \\
9.01 \\
5.91 \\
4.7 \\
5.7 \\
5.6 \\
5.6 \\
7.01\end{array}$ & $\begin{array}{l}\text { Marked } \\
\text { Marked } \\
\text { Marked } \\
\text { Moderate } \\
\text { Moderate } \\
\text { Moderate } \\
\text { Marked } \\
\text { Marked } \\
\text { Slight } \\
\text { Marked } \\
\text { Marked } \\
\text { Marked } \\
\text { Marked }\end{array}$ & $\begin{array}{l}\text { Very slight } \\
\text { Marked } \\
\text { Moderate } \\
\text { Slight } \\
\text { Very slight } \\
\text { Very slight } \\
\text { Moderate } \\
\text { Marked } \\
\text { Verys light } \\
\text { Veryslight } \\
\text { Slight } \\
\text { Slight } \\
\text { Moderate }\end{array}$ \\
\hline
\end{tabular}

TABLE $V$

Casfs Examined Nine to Twelve Months after Operation

\begin{tabular}{|c|c|c|c|c|c|c|c|c|c|}
\hline \multirow{2}{*}{$\begin{array}{l}\text { Case } \\
\text { No. }\end{array}$} & \multirow{2}{*}{$\begin{array}{c}\text { Age } \\
\text { (Years) }\end{array}$} & \multicolumn{2}{|c|}{ Gain in } & \multicolumn{2}{|c|}{$\begin{array}{l}\text { Haemoglobin } \\
\text { Level }(\%)\end{array}$} & \multicolumn{2}{|c|}{$\begin{array}{l}\text { Erythrocyte Count } \\
\text { (m. per c.mm.) }\end{array}$} & \multicolumn{2}{|c|}{ Cyanosis } \\
\hline & & $\begin{array}{l}\text { Height } \\
(\mathrm{cm} .)\end{array}$ & $\begin{array}{l}\text { Weight } \\
\text { (kg.) }\end{array}$ & Before & After & Before & After & Before & After \\
\hline $\begin{array}{r}2 \\
6 \\
11 \\
14 \\
26 \\
31\end{array}$ & $\begin{array}{c}5 \\
12 \frac{1}{2} \\
6 \\
6 \\
3 \\
12\end{array}$ & $\begin{array}{c}4 \\
7 \frac{1}{2} \\
4 \\
7 \\
14 \\
6\end{array}$ & $\begin{array}{l}3 \\
8 \\
1 \frac{1}{2} \\
4 \\
4 \\
4 \frac{1}{2}\end{array}$ & $\begin{array}{l}145 \\
112 \\
125 \\
148 \\
139 \\
147\end{array}$ & $\begin{array}{l}120 \\
112 \\
100 \\
115 \\
118 \\
120\end{array}$ & $\begin{array}{l}7.3 \\
5.42 \\
5.5 \\
9.32 \\
9.54 \\
8.17\end{array}$ & $\begin{array}{l}5.21 \\
5.15 \\
4.69 \\
5.74 \\
6.7 \\
7.4\end{array}$ & $\begin{array}{l}\text { Marked } \\
\text { Moderate } \\
\text { Moderate } \\
\text { Marked } \\
\text { Marked } \\
\text { Marked }\end{array}$ & $\begin{array}{l}\text { Slight } \\
\text { Very slight } \\
\text { Slight } \\
\text { Slight } \\
\text { Slight } \\
\text { Slight }\end{array}$ \\
\hline
\end{tabular}

TABLE VI

Cases Examined Twelve Months or More after Operation

\begin{tabular}{|c|c|c|c|c|c|c|c|c|c|}
\hline \multirow{2}{*}{$\begin{array}{l}\text { Case } \\
\text { No. }\end{array}$} & \multirow{2}{*}{$\underset{\text { (Years) }}{\text { Age }}$} & \multicolumn{2}{|c|}{ Gain in } & \multicolumn{2}{|c|}{$\begin{array}{l}\text { Haemoglobin } \\
\text { Level }(\%)\end{array}$} & \multicolumn{2}{|c|}{$\mid \begin{array}{c}\text { Erythrocyte Count } \\
\text { (m. per c.mm.) }\end{array}$} & \multicolumn{2}{|c|}{ Cyanosis } \\
\hline & & $\begin{array}{l}\text { Height } \\
\text { (cm.) }\end{array}$ & $\begin{array}{c}\text { Weight } \\
\text { (kg.) }\end{array}$ & Before & After & Before & After & Before & After \\
\hline $\begin{array}{r}4 \\
7 \\
9 \\
10 \\
18 \\
20 \\
22 \\
28 \\
32\end{array}$ & $\begin{array}{r}10 \\
11 \\
12 \\
10 \\
6 \\
20 \\
4 \\
20 \\
20\end{array}$ & $\begin{array}{l}4 \\
3 \frac{1}{2} \\
6 \\
3 \\
6 \frac{1}{2} \\
4 \\
1 \\
-\end{array}$ & $\begin{array}{l}6 \frac{1}{2} \\
7 \\
6 \\
6 \frac{1}{2} \\
3 \\
9 \\
5 \\
2 \frac{1}{2} \\
-\end{array}$ & $\begin{array}{l}140 \\
135 \\
110 \\
171 \\
140 \\
155 \\
132 \\
105 \\
120\end{array}$ & $\begin{array}{r}105 \\
110 \\
105 \\
156 \\
140 \\
138 \\
105 \\
135 \\
93\end{array}$ & $\begin{array}{l}6.3 \\
8.5 \\
5.22 \\
7.33 \\
8.25 \\
8.8 \\
6.28 \\
7.2 \\
5.25\end{array}$ & $\begin{array}{l}5.2 \\
4.8 \\
4.87 \\
7.2 \\
8.97 \\
7.6 \\
4.91 \\
6.06 \\
4.91\end{array}$ & $\begin{array}{l}\text { Moderate } \\
\text { Marked } \\
\text { Marked } \\
\text { Marked } \\
\text { Marked } \\
\text { Marked } \\
\text { Marked } \\
\text { Moderate } \\
\text { Moderate }\end{array}$ & $\begin{array}{l}\text { Very slight } \\
\text { Very slight } \\
\text { Slight } \\
\text { Moderate } \\
\text { Marked } \\
\text { Moderate } \\
\text { Very slight } \\
\text { Slight } \\
\text { Nil }\end{array}$ \\
\hline
\end{tabular}

In the case of H.P. J. (Case 37) an exploratory thoracotomy only was performed, and his condition after operation was quite unchanged. 
Tables III, IV, V, and VI show the changes which were observed in the height and weight, haemoglobin level, erythrocyte count, and degree of cyanosis before and after operation. In 32 of the 35 cases a Blalock operation was performed, and in one case, H. V. L. (Case 38), a pleural stripping operation (Barrett) was done. In Cases 24 and 37 it was impossible to perform any type of anastomosis.

It will be seen that over the whole series there is a distinct improvement in height and weight following operation, and in some cases the improvement is so great that it is sometimes difficult to recognize the patient at the follow-up examination.

Most of the cases show also a considerable drop in the haemoglobin level and in the erythrocyte count, and whilst this generally gives an indication of the success of the operation, there are in this series exceptions, and cases have been seen where an excellent functional result has been obtained but in which the haemoglobin level and the red cell count have remained high. Such are Cases 18 and 19.

In one (Case 32) the colour could only be classed as normal, while in nine there was a very slight degree of cyanosis which could be seen only in the fingers and toes. In 13 cases the cyanosis was seen as a tingeing of the lips and cheeks, and this was classed as "slight," while in the eight "moderate" cases there was still a distinct blueness of the complexion. Three cases remained " marked" and unchanged.

Exercise Capacity.-The same difficulties which are experienced in assessing exercise capacity before operation occur in the later examinations, and one must largely be dependent on the patient's or parents' history for this information. Again, arbitrary levels had to be made in the classification, and we placed patients who were able to walk $4 \mathrm{~km}$. or more at a normal walking pace as having a "very good" exercise capacity. It may be added that all these patients were able to play with other children, or, in the case of adults, to live a more or less normal life within limits. Most of them were able to ride a cycle without trouble. Two outstanding cases were those of E. A. (Case 6) and G. L. A. (Case 32). E. A. had been confined to her room for four years before operation but now is capable of walking $10 \mathrm{~km}$. "with ease." G. L. A. is perhaps more astounding as he has recently cycled $140 \mathrm{~km}$. in a day with a five-minute rest each hour. He complained that his main trouble now was flat feet. Ten of the cases fulfilled these conditions.

A "good" exercise capacity mark was given to those patients who, while incapable of the exertion of the higher group, were nevertheless able to go about their daily task without distress. In the case of children they were capable of playing with other children and were attending school regularly. They were able to walk at least a kilometre at normal walking pace and to climb a flight of stairs without distress. Fifteen cases were placed in this category.

Some children were able to walk about quietly and go to school, but on attempting to run became quickly breathless and sometimes cyanosed. They also volunteered the information that, while they were able to run a little, they had to take a rest " now and then." These were classed as "fair."

Only two cases showed no change, and these were considered "poor." They included H. M. M. (Case 24), in which no anastomosis could be done.

On this basis the exercise capacity after operation was found to be as follows:

10 cases (Nos. 4, 6, 7, 11, 13, 14, 16, 18, 32, and 36)-very good.

15 , (Nos. 1, 2, 8, 9, 17, 19, 20, 22, 25, 26, 28, 30, 33, 34, 35)-good.

8 " (Nos. 10, 12, 27, 31, 37, 38, 39, and 40)-fair.

$2 "$ (Nos. 3 and 24)-poor. 
Cardiac Enlargement after Operation.-Of the 32 patients subjected to the Blalock operation, 24 showed clinically and radiologically no evidence of cardiac enlargement at the time of the follow-up examination. Of the remaining eight cases, six showed slight enlargement only (Cases 2, 8, 13, 16, 27, and 34).

Only in Cases 28 and 35 was there seen a fairly marked degree of enlargement, and in the former the enlargement affected both ventricles, especially the left, and in the latter the left ventricle only. A point of some interest arises from this. It is surprising how seldom during catheterization of the heart the catheter enters the aorta, but in both these cases it was seen to do so. In Case 21 it was also possible to pass the catheter into the aorta, and at necropsy it was found that both the pulmonary artery and the aorta arose from the right ventricle, and that the left ventricle was a small, thin-walled chamber; death was due to acute left ventricular failure. We feel that in Cases 28 and 35 the catheter entered the aorta because the artery was markedly dextroposed, or, in other words, because the aorta arose more from the right ventricle than the left, and the gross enlargement of the left ventricle which occurred after operation could be due to the fact that in these cases there was a poorly developed left ventricle such as was seen in Case 21. It is possible that in these cases the shunt operation places a load on the left ventricle that it is incapable of bearing.

Auscultation of the Heart.-In 30 of the 32 patients in whom an anastomosis was performed, it was possible to hear the murmur, caused by the artificial ductus, with a stethoscope. In most cases the murmur was similar to the continuous machinery-like hum of the patent ductus arteriosus, but in a few instances it was heard as a faint diastolic bruit, which was loudest in the axilla on the operated side,

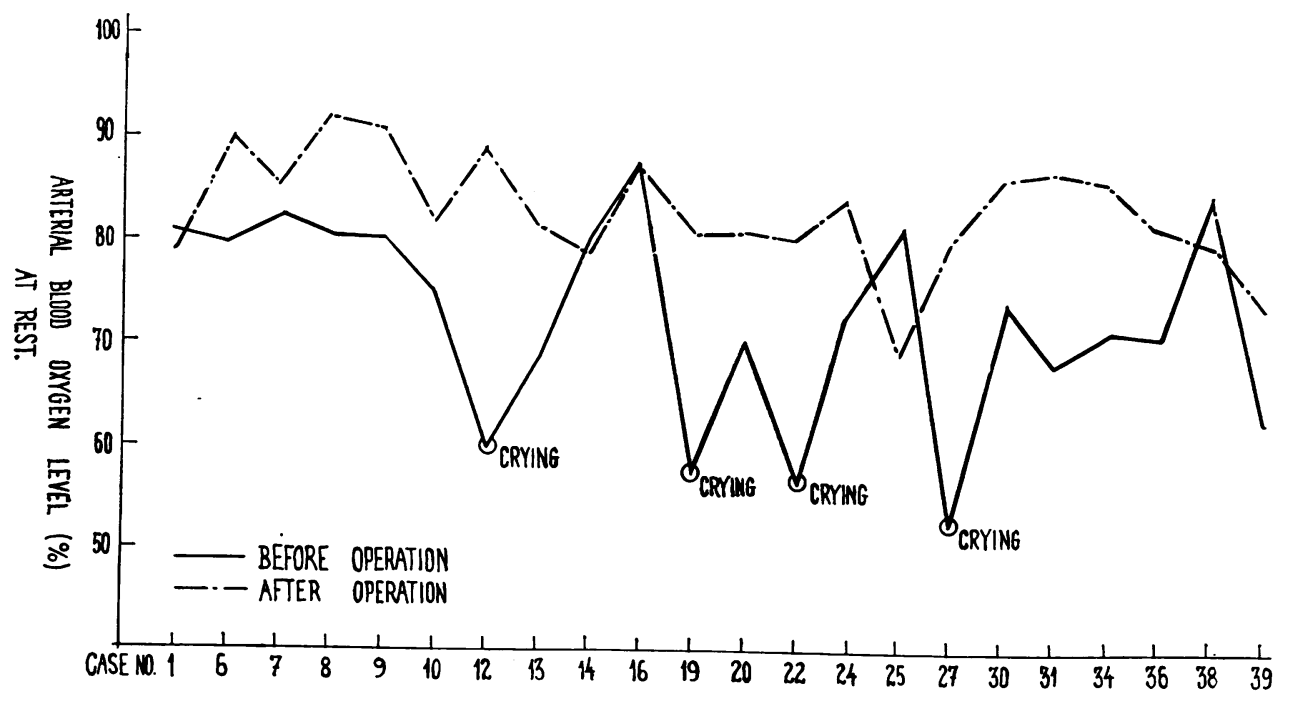

Fig. 1.-A figure showing the comparative arterial blood oxygen saturation levels in 22 of the operated cases before and after operation. 
or just medial to the upper medial edge of the scapula posteriorly. In two (Cases 3 and 18) no murmur was audible, and from other signs in these patients there is little doubt that the shunt was not functioning.

Changes in Arterial Blood Oxygen Saturation Levels.-An arterial puncture was made before and after operation in most cases, and from the specimens obtained the arterial oxygen saturation was estimated. In some this was impossible, especially in the younger children, on account of their kicking and struggling when the attempt was made.

In Fig. 1 the resting arterial oxygen level is shown diagrammatically in 22 of the cases before and after operation, and it is apparent that the effect of operation is on the whole to raise that level, but from our observations in this series the clinical improvement is not always proportionate to the rise in the resting arterial oxygen level. Thus it is seen that in Case 7, clinically one of the most successful we have had, the effect of operation was to raise the oxygen level from $82 \%$ to $85 \%$, and yet previously the patient had been totally incapacitated. Similarly Case 16 showed no change in the resting blood oxygen level, but the clinical improvement was dramatic. In one patient (Case 25) the post-operative oxygen level was actually a little lower than the pre-operative level three months after operation, but the clinical improvement was obvious. A further test carried out on this patient six months later showed then that the resting oxygen level had been slightly raised.

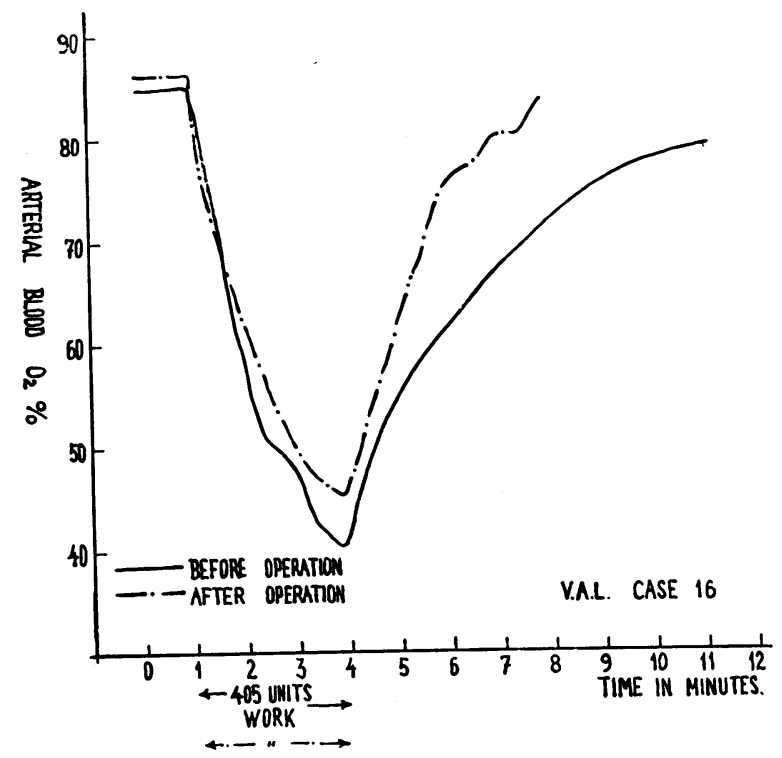

FIG 2-This shows the oximeter curves before and after operation in one of the successful cases. It will be noted that the fall in the arterial blood oxygen level is little changed by operation, but the quicker " recovery time" for the restoration of the blood oxygen level is clearly seen. The figures shown for the amount of work done, in this and subsequent curves, represent the work done per minute over the period indicated by the arrows.
The highest resting oxygen level seen before operation was that in Case 16, where it was $87 \%$, while the lowest was $54 \%$ (Case 26). Lower levels than this were encountered but were ignored on account of the distress of the patients at the time of arterial puncture. The highest post-operative level was $92 \%$ (Case 8), and there was an overall average increase of about $10 \%$ in the resting oxygen level.

The oximeter has made possible the observation of changes in the oxygen saturation level of these patients while at work, and, by giving them an exactly similar amount of work before and after operation, to compare the results. The dramatic fall which occurred in patients preoperatively soon became well known, and in the early cases 
we took as an arbitrary figure a drop of $20 \%$ in the arterial oxygen level on light work, other things being equal, as an indication for operation. Such curves are seen in Figs. 2 and 3, where it may be seen that, while working, the oxygen level fell from $85 \%$ to $40 \%$ and $63 \%$ to $40 \%$ respectively. The symptoms of the patient are due to this fall in oxygen saturation.

In our investigations after operation we have found that this oxygen saturation fall during exercise still occurs, and while the extent of the fall is usually less and at a higher level (in some cases it is considerable) nevertheless the patients are clinically improved (Figs. 2 and 3). In Fig. 2 it is seen that while the pre-operative drop in the oxygen level is from $85 \%$ to $40 \%$, post-operatively it is from $87 \%$ to $45 \%$, and in Fig. 3 that the pre-operative fall was from $63 \%$ to $40 \%$, and the post-operative from $73 \%$ to $48 \%$. We have observed on numerous occasions similar post-operative falls in the blood oxygen level, both in the present series and in cases operated upon later.

It would seem clear from the great clinical improvement in these cases, and by their being able to withstand an increased amount of active exercise compared with before operation, that the fall in the oxygen saturation level is not the sole factor of importance, and from the comparison of the oximeter curves before and after operation the most notable change is in the "recovery time" factor. Thus in Case 16 (Fig. 2), before operation an interval of five minutes was required after exercise for the blood oxygen to be restored to a level of $70 \%$, after operation the time required was only two minutes, and yet the extent of the fall was almost the same. Similarly in Case 39 (Fig. 3), it is seen that the "recovery time" has been reduced from eight to four minutes. The former case, with a quicker recovery time of two minutes, showed a better clinical result than the latter, despite the fact that the fall in the level of blood oxygen was greater in the former and the level reached lower. Fig. 4 shows the pre- and post-operative oximeter curves of Case 25. An almost equivalent fall is found after operation, although at a higher level, but the shorter "recovery time" is clearly seen when the quickly rising post-operative curve is compared with the more gradual pre-operation one. The patient volunteered the information that she did not now have to take short rests so often after effort, or for so long.

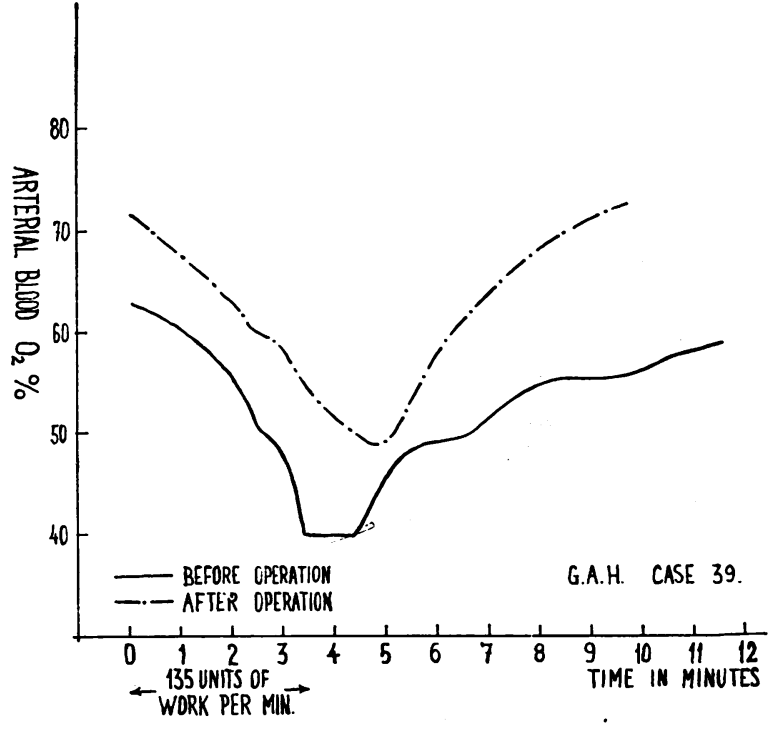

FIG. 3.-This figure shows the pre- and post-operative oximeter curves in another successful case. Again the considerable post-operative fall in blood oxygen is shown, with the improved " recovery time." 


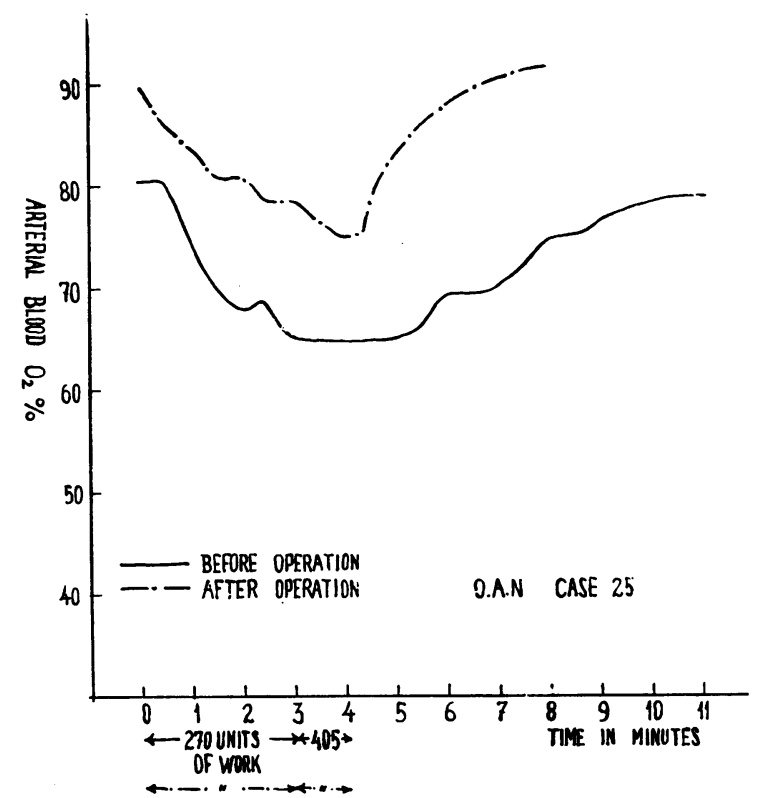

FIG. 4.-Another example of an oximeter curve before and after operation. The resting arterial oxygen level has been raised by $10 \%$, but the fall on identical work is about equivalent to that before operation. The rapidity of the blood oxygen restoration after operation compared to that before operation is clear.
Figs. 5 and 6 show the post-operative oximeter curves of Cases 9 and 30, two of the best clinical results in the series. Unfortunately an oximeter curve could not be made in these two patients before operation. They were both severe cases, the former not having left her bedroom for four years before operation, and the latter was able to walk only three paces before squatting. In our experience it usually requires six or seven minutes on the average in these cases of Fallot's disease before operation for the blood oxygen to return to its " normal " level after exercise, so that it would seem reasonable to suppose that in these two patients the time required would be at least near that figure. From the curves in Figs. 5 and 6 it is apparent that, whilst the arterial oxygen fall on exercise

is great after operation, the " recovery time" is only three minutes and two minutes respectively, and that in both cases within one minute of the cessation of exercise there has been a rapid restoration of the blood oxygen level. Thus it would appear that in some cases at least after the Blalock operation for pulmonary stenosis the clinical improvement is not due so much to a raising of the blood oxygen content, or the prevention of the severe fall that occurs in the blood oxygen on exercise, as to a shortening of the time required for the oxygen of the arterial blood to restore itself to its former level.

Fig. 7 shows the only case in the series where little or no fall occurred in the oxygen level after exercise. As the oximeter curve suggests, the functional result was an excellent one, and from being confined to the house for four years the patient is now able to walk $10 \mathrm{~km}$. without trouble.

\section{Final Analysis of Results}

Forty cases have been operated upon with five deaths, and the remaining 35 patients have been investigated. In assessing the result of operation, an attempt has been made to view each case as a whole, giving due regard to improvement in colour, height, and weight increase, absence or sign of cardiac insufficiency and so on, as well as to the important feature of increased or unchanged exercise capacity. 
Fig. 5.-The post-operation oximeter curve of a patient who had been totally incapable of exercise before operation, but is now capable of considerable activity. Note the large fall in the oxygen level and the quick " recovery time."
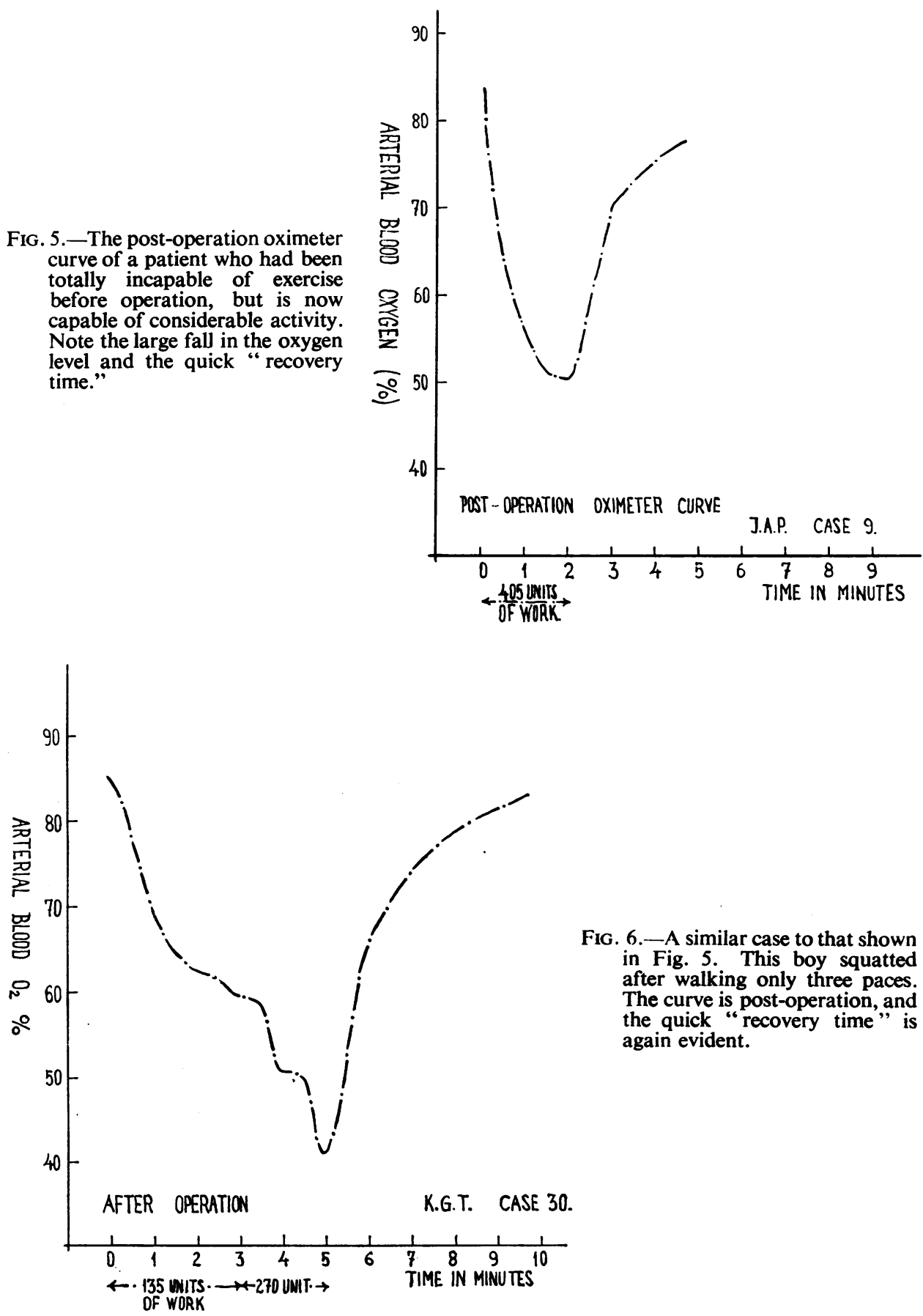

FIg. 6. - A similar case to that shown in Fig. 5. This boy squatted after walking only three paces. The curve is post-operation, and the quick " recovery time" is again evident. 


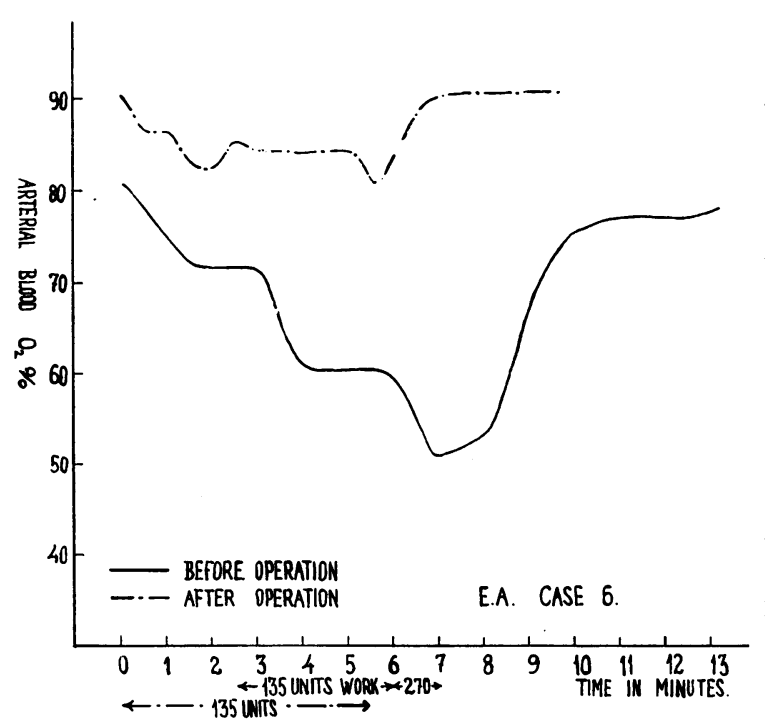

FIG. 7.-This shows the pre- and post-operative oximeter curves of a girl aged 12 years who had been confined to her bedroom for a period of four years before operation, and is now able to walk $10 \mathrm{~km}$. "with ease." This type of post-operation curve with the very slight fall of oxygen level has been rare in the series.
Eight cases (Cases 4, 6, 7, 25, $26,30,32$, and 36 ) are considered to have given excellent results. Ten cases (Cases 9, 11, 13, 14, 16, $17,22,31,33$, and 34) are considered to have given very good results. Six cases (Cases 1, 2, 8, 19, 20, and 39) have given good results. Eight cases (Cases 10, $12,18,27,28,35,38$, and 40 ) have given fair results. Two cases (Cases 24 and 37) upon which a thoracotomy only was performed remain unchanged. One case (Case 3) is considered a poor result.

\section{SUMMARY}

An analysis has been made of 40 cases of persistent cyanosis investigated at the Rigshospital, Copenhagen, and operated on, with five deaths, in the Department of Thoracic Surgery of that hospital. The cases comprised 35 cases of the tetralogy of Fallot, two cases of pulmonary arterial stenosis with intra-atrial septal defect, two cases of under-developed right ventricle, and a third case in which the pathology was doubtful.

An attempt has been made to subdivide the cases into degrees of incapacity, cyanosis, and age at operation, with age-death incidence.

A comparison has been made between the haemoglobin level, erythrocyte count, and oxygen saturation level before and after operation, and attention has been drawn to the difference in the time required for the restoration of the blood oxygen level. It would appear that in many cases the operation does not materially aiter the blood oxygen level, but shortens the time required for the arterial blood oxygen to regain its pre-exercise level.

The incidence of precordial thrill (34\%) and of systolic murmurs has been given in the series, and radiological findings have been analysed giving a fairly characteristic picture in $83 \%$ of the cases of Fallot's disease.

Mention has been made of the surgical technique employed with special reference to the approach of choice favoured and the reason for it and of the anatomical abnormalities encountered. In four cases it was impossible to perform an anastomosis, and the reasons are explained.

A follow-up examination has been made, and the incidence of cardiac enlargement following operation has been given. 
A final analysis of operation results has been made. Eight cases were considered excellent, ten were considered very good, six were good, and eight were considered to have given a fair result. One case gave a poor result and two were unchanged.

I should like to express my gratitude to Professor E. Husfeldt, Professor of Surgery at the University of Copenhagen, in whose department these patients have been, for his kindness in giving his permission for the publication of this paper and for his helpful suggestions and criticism.

\section{REFERENCE;}

Barrett, N. R., and Daley, R. (1949). Brit. med. J., 1, 699.

Blalock, A. (1947). J. thorac. Surg., 16, 244.

- and Hanlon, C. R. (1948). Surg. Gynec. Obstet., 87, 183.

Murray, G. (1948). Canad. med. Ass. J., 58, 10.

Potts, W. J. (1947). J. int. Coll. Surg., 10, 569.

Pugh, D. G. (1947). Proc. Mayo Clin., $22,174$.

Taussig, Helen B. (1947). Congenital Malformations of the Heart. New York.

- (1947). Bull. N.Y. Acad. Med., 23, 705. 